\title{
Personality-oriented education as a factor of sustainable development of the higher education system
}

\author{
Irina Burlakova ${ }^{1, *}$, Galina Khoroshavina ${ }^{2}$, and Lyudmila Anisimova ${ }^{3}$ \\ ${ }^{1}$ Federal State Budget Educational Institution of Higher Education «K.G. Razumovsky Moscow State \\ University of Technologies and Management (the First Cossack University)», 109004 Moscow, \\ Russia \\ ${ }^{2}$ Bauman Moscow State Technical University (National Research University), 105005 Moscow, \\ Russia \\ ${ }^{3}$ Moscow State Regional University, 105005, Moscow, Russia
}

\begin{abstract}
The scientific and methodological basis of the modern concept of higher education is the synergetic unity of classical and modern psychological and pedagogical approaches. Modern higher education is focused on introducing a young person to fundamental knowledge, on developing practical skills in future professional activities and preparing them for lifelong learning. However, modern education is not focused on the student's life and professional self-determination. The integrated use of personality-oriented technologies in the educational process helps to stimulate the development of personal potential, mental activity, "launches" the development of cognitive processes, and contributes to the formation of competencies necessary for a future specialist. Personaloriented education at the University will help to the painless entry of a young specialist into professional activities and professional community.
\end{abstract}

\section{Introduction}

The scientific and methodological basis of the modern concept of higher education is the synergy of classical and modern psychological and pedagogical approaches: humanistic, competence-based, axiological, activity-based, personality-oriented, individual. The implementation of such approaches as humanistic and competence-based makes it possible to answer questions about the purpose and results of education in a global competition. First of all, higher education in the modern context is focused on introducing a young person to fundamental knowledge (although this has become increasingly rare in recent years due to the reduction in the number of hours spent on classroom work), on developing practical skills in future professional activities and preparing them for lifelong learning. However, it is worth noting that modern education is not focused on the life and professional selfdetermination of the student, and, moreover, we have to state that he is not yet ready for independent development of knowledge. Potential graduates are often not ready practically

* Corresponding author: iiburlakova@mail.ru 
and psychologically to work in the received specialty. Therefore, the acquisition of knowledge and skills is not only the goal of education, but also a means to achieve longterm and long-term goals in the professional sphere.

\section{Research methodology}

\subsection{Object and subject of research}

In this article, the object of research is higher education. The subject of the research is the personality-oriented higher education of future teachers.

\subsection{Research material}

Study of psychological, pedagogical and methodological literature, surveys of students and young teachers, questionnaires.

\subsection{Method of research}

The article used methods of observation, analysis of surveys and questionnaires, interpretation of the obtained material, and included observation.

\section{Study results}

The axiological approach is aimed at determining the values of education, which have changed significantly in recent times. In the conditions of poor professional training of school leavers, most of the applicants face the problem of ignorance of what they want, indifference, fatigue after exams, apathy. Admission to the university in this situation is often connected not with the purpose of self-fulfillment and life self-determination, but with the fact where the student passed on points on the budget or where there was enough money for paid education. It is sad that already in 1 and 2 courses students are looking for earnings. For example, future teachers are actively engaged in tutoring and, most importantly, their employers are not interested in the professional unpreparedness and methodical illiteracy of students whom they trust their children. The value of higher education, on the one hand, is high, because most school leavers want and are determined to get a quality higher education. On the other hand, not the willingness and desire of many students to go to work in the specialty after graduation and an attempt to change the profession is observed when entering the master's programs $[1,2]$.

The individual approach is focused on the development of individual-personality abilities of the learner and involves creating adequate conditions for training. However, it is necessary to take into account the social order of the state to train competitive specialists for a certain sector of the economy or social sphere. In this regard, it is advisable to develop the individuality of the future specialist, taking into account the social order and requirements of potential employers to the set of professional qualities, which involves the design of a socially-oriented, cultural-personal model of higher education [3]. Under the approach under consideration, the success of the model can be achieved through the development of an individual style of study, which is formed with individual characteristics. Individualization of student training programs in any field will give an 
opportunity to bring knowledge to the same level in each course. Individualization of education, its personal-oriented orientation will be a way out of the difficult situation.

An active approach to teaching contributes to the assimilation of knowledge and the formation of professional skills through independent activity under the direction of the teacher. The active approach is a priority in the modernization of higher education. Its meaning is that the student's personal abilities are manifested and developed only in activities and through activities. At the same time, the basis of the development of the future teacher's personality is the activity that fully corresponds to his interests and abilities. An active approach in education involves learning using a variety of interactive methods. Interactive learning, in general, is based on an individual increase in the volume of subject knowledge, so the traditional form of learning is replaced by interactive methods with intensive intragroup interaction taking into account the individual characteristics of the student. The use of interactive methods involves the schematic interaction of "teacherstudent" and "student-student," "student-student" and is based on the selection and definition of interpersonal communication, the ability to accept the role of another. Interactive learning methods are interaction, collaboration, search, interpersonal dialogue, play between a person and the information environment. Active and interactive learning methods increase the absorption of the amount of material to 90 percent, based on visual aids, posters, maps and models. Interactive teaching methods - games, discussions, staging, trainings, trainings - require the use of special techniques, but only when taking into account the individual characteristics of students.

The situation in the group should focus the student on empathy, providing mutual assistance. As a result, every young person begins to feel useful, seeks to make a personal contribution to the common cause and be interested in the results of teamwork. Interactive practice sessions in a foreign language prevent the perception of classes as a boring necessity. Due to the interaction, the material is presented in a bright and figurative form, so that the student's cognitive activity is always at a high level, and in parallel the skills of interpersonal communication and collaboration are formed.

Personality-oriented education in the active approach is the subjectification of the learning process, which emphasizes the self-value of each student regardless of their abilities and abilities. In other words, personal-oriented education needs to take into account the characteristics of the subject of educational activity. In general, it is a different "learning organization methodology" that aims to use the personal potential and subjective experience of the learner in achieving the planned results. "The goal of personal-oriented education is the need to "lay" in the learning mechanisms of self-development, adaptation, self-realization, self-regulation, self-education, necessary both for the formation of personality and for professional self-determination." [4].

Personal-oriented education has the following functions:

- the humanitarian function involves the self-worth of a person and ensuring his physical and spiritual and moral health, understanding the values of professional self-determination and the possibility of maximizing their own personal potential for the purpose of professional development. Mechanisms for the implementation of this function are communication of students in a group, mutual understanding, cooperation and co-creation in the process of interactive learning;

- cultural function contributes to the preservation, transmission, reproduction and development of one's own culture and to the cultural culture of the country studied by means of education in order to engage in dialogue between cultures and students. Mechanisms for the implementation of this function are cultural self-identification, acceptance of the values of the people of their country, the broadcasting of cultural and historical values, as well as understanding the cultural context of any country and building professional activities taking into account knowledge of foreign-speaking culture; 
- the socializing function is aimed at the individual's assimilation and reproduction of social experience in the process of obtaining education, necessary and sufficient for a person to enter the life of the professional community and into the future profession. Mechanisms for the implementation of this function can be: preservation of individuality, constant reflection, creative attitude to educational activities and professional self-determination of the student from the 1st year [5].

It is not possible to implement the functions of personal-oriented education in the context of the administrative-command system of management of the educational activities of students, as personally oriented education implies a change in the position of the teacher, which is:

- purposeful building of subject-subject relations in the educational process, when the student takes responsibility for the results of his own educational activities, is able to independently master a certain teacher's amount of knowledge, is active in the choice of forms, means and methods of learning, has the skills of control and self-control;

- having an optimistic view of the abilities of each student, respectful and invaluable attitude to the choice of the future profession, the desire of the teacher to see promising lines of personal growth of each student in the context of his future profession, the ability to motivate students to further self-education;

Disclosure of personal meanings and interest in cognitive and reflective activities, promoting the socialization of each student, incorporating him into the professional community and accepting professional values.

The content of personal-oriented education differs significantly from the content of those working programs, which are presented in most universities. This feature causes difficulties in the professional adaptation of the student. The content of personal-oriented education is aimed at helping the student to build a personal trajectory of development, to determine his own potential and attitude to the resulting profession, which implies: the choice of values of self-important, mastering the system of knowledge and skills, mastering ways of solving interesting scientific problems, reflecting his own self-position in relation to the chosen profession.

Personal development and professional self-determination are a criterion for the effectiveness of personal-oriented education.

Thus, summarizing the above, we define personal-oriented education as a purposeful process of interaction between the subjects of education - future teachers, focused on personal and professional development and self-development of the learner.

Personal-oriented education is organized on the basis of certain pedagogical technologies, which are oriented to the interests of the student, whose unique personality becomes the center of the educational process. Under the created conditions, "... young people strive to maximize their possibilities (self-actualization), is open to the perception of new experiences, capable of conscious and responsible choice in a variety of life situations." [6].

Personality-oriented learning technologies are aimed at personal development, individuality, self-reliance, responsibility, creativity [4-9].

Personality-oriented learning technologies incorporate methods that correspond to the individual characteristics of students and change the organization of educational activities in general. Personally oriented education presents certain difficulties for its organization, both methodologically and methodically. Such activities involve the use of special supports, ideas and methods of action, which are aimed at ensuring and supporting the processes of self-knowledge and self-fulfillment of the personality of each learner. Personality-oriented technologies enable the teacher to create conditions for cooperation and co-creation, selfactualization and self-development of the individual in the classroom. We include such technologies: case - psychological and educational technologies, SCRUM-technology, 
training in collaboration, portfolio of achievements, gaming technologies, problem learning technologies, design technologies and others [1, 2, 10-14].

Unlike the traditional, personality-oriented class, the degree of interaction in the "teacher-learning" system completely changes the degree of interaction. The teacher is forced to replace the authoritarian style of management of the educational process with a style of cooperation and co-creation, focusing on the procedural activity of the student, rather than on the analysis of the results. The student's position also changes - from the executor of the teacher's requirements he goes to active participation in the learning process, creative attitude to learning, responsibility for the results of his own educational activities. In personal-oriented learning, we see an interesting process of naming the thinking of the learner, which becomes more reflexive, critical and creative (creative). The nature of the relationship between the teacher and the student, as well as in the group between the students become trusting and open. In such conditions, the teacher does not provide students with ready knowledge, but creates conditions for optimal personal development of students and self-education in the process of learning a foreign language. The teacher's monologue in class changes to dialogue and polylogue in the group. Together with the students, he selects the content of the material that needs to be learned and determines the amount of time to complete the tasks. Only with this condition, the assimilated knowledge becomes personal and meaningful. The teacher in such a class creates conditions for personal-oriented education. He fully manages the learning process, planning and organizing activities, advising and removing the difficulties that students necessarily face in the process of learning some facts.

In the context of personal-oriented education, special attention should be paid to modular technologies, as many universities today, as part of the implementation of the new higher education standard, are moving to modular education. In our opinion, modular technology is effectively used to develop cognitive activity of learners. "It contributes to the development of each student's personal motivational sphere, his intellect, independence, and ability to manage his own educational and cognitive activities. Whatever we use pedagogical technologies, they will then be successful in personal-oriented learning, when they include a reflection in which the learner is aware of his self-worth and is responsible for the results of his own learning activities" [7].

"Modular learning technologies are the implementation of the learning process through the division of it into "functional nodes" - professionally significant actions and operations that are performed by the student, which allows to achieve the planned results of training. The essence of modular learning is that it allows each student to achieve their own specific goals in learning and learning activities." [15].

Modular training contributes to the development of self-reliance, responsibility, assimilation of professionally significant knowledge and skills, which students extract their own educational and educational work. The teacher in modular training organizes the educational process both in the area of near development, and in the area of prospective development of the student. This training is based on already developed thought processes and processes that are just developing or actualized, being in a passive phase. The use of modular technologies contributes to the formation of a sustainable motivation to learn a foreign language. The main difficulty in using modular training is the competent "docking" of professional-oriented modules.

Personal-oriented training based on modular technologies is based on the following principles:

- designing the training material in such a way as to ensure that the intended results are achieved;

- presentation of educational material in logical and complete blocks;

- integrating different methods, tools and forms of learning; 
- singing separate elements from the content of the material to set multi-level didactic tasks (complex, integrated, private) on an individual student, student group or stream;

- openness of information, ability to change the form of its presentation;

- adaptability and comfort of the student through the analysis of each stage of study;

- the formation of an individual style of learning activities through the focus of training on the development of the student's personality;

- encouraging active cognitive activity through the motivation of the learner in the process;

- the versatility of methodical accompaniment lies in the fact that each module contains memos, recommendations, supports, thesaurus, which can facilitate the assimilation of a large amount of information" [16].

By organizing training on the basis of modular technologies in the conditions of personaloriented education, the teacher takes on new functional responsibilities:

- management of the educational and cognitive activities of the student, i.e. the teacher ceases to be a carrier of information and knowledge and becomes the organizer of the student's educational and educational activities;

- motivation of students' learning activities through constructive communication, emotional uplift and cooperation of students with each other;

- self-employed work in both classroom and non-audit work, including the use of additional training tools;

- use a creative approach to the organization of collective (group) ways of teaching students, individual forms of work with students when it is necessary to provide advice, additional assistance to lagging students, or in working with gifted students in the preparation and implementation of an individual research project;

- creating success situations for each student, i.e. developing individual assignments adapted to the characteristics of each student;

- the organization of reflection of students' educational and educational activities and the formation of adequate self-esteem among students" [15].

After the creation of new content of the class, differentiation of educational material in accordance with the abilities and abilities of students, as a rule, determines the order of forms of work with educational material, there is a choice of additional means of training and technologies to optimize educational activities. At the final stage of preparation, the teacher creates a technological map of the educational (subject) module, which contains a list of topics, competencies, planned results, etc. [16].

Also, in the system of personal-oriented education, the teacher's creation of certain conditions for the manifestation of educational and educational activity of each student plays an important role.

These conditions may include:

- to reveal the subjective experience of students allows the use of a variety of forms of methods of organizing educational and educational activities;

- the session will be effective, provided it is created a creative atmosphere;

- stimulating students to express their own thoughts removing the psychological fear of error;

- use of didactic material in the class, which will allow the student to choose the most important content of the educational material for him;

- when assessing the assessment, the teacher takes into account the result in the process of achieving it;

- motivational encouragement of the student, who tries to find his own individual style of work, analyzes the achievements of his classmates, chooses and masters the most rational ways of learning;

- use of developed cases or learning situations in classroom work that contribute to the ability of each student to show creativity, and independence and initiative. [6]. 


\section{Discussion of results}

The criteria for the effectiveness of personal-oriented classes will be: priority choice of problematic tasks; exercise that allows the learner to choose the form of work with the educational material and additional means of training; positive emotional mood of all students in class; group discussion at the end of the class and discussion of what I liked or disliked in class; assessing not only the correct answer during the survey, but also an analysis of how the student thinks about how far he has progressed in mastering communication competence; when determining the amount of homework and explaining the adeniums that the student needs to perform, explains in detail how to organize the training work at home and rationally allocate the time to finish the optimal result [17].

It should be noted that it is the creative approach of the teacher to the organization of the training session and the optimistic attitude to performance will contribute to a positive change in the attitude of students to the difficult and long process of teaching, both in the process of classroom and in extra-audit work, and the personal-oriented approach will allow to activate mental activity, self-creation, to identify the hidden possibilities of each student, will make him a co-author in the design of the class.

\section{Conclusion}

Thus, purposefully organized personal-oriented training of future teachers will allow to motivate students, develop a steady interest in the subject, improve knowledge, hone communication skills. Such classes contribute to the development of the skill of self-study material, and collective forms of education, which are mandatory in the organization of personal-oriented education teach students to constructively solve disputes and misunderstandings arising in the course of problem situations, rising to a higher level of communication and academic success.

Comprehensive application of personal-oriented technologies in education, both in the process of classroom and non-audit work allows to stimulate the personal development of each student, his intellectual activity, promotes the comprehensive development of cognitive processes, forms the competences that are necessary for the future teacher. Personal-oriented education at the university provides an opportunity to remove or at least reduce the fear of the future teacher before the school, in front of modern children and helps the painless entry of a young foreign language teacher into professional activities and the professional community.

\section{References}

1. Principles behind the Agile Manifesto Agile manifesto 2018, http://agilemanifesto.org/principles.html?source=post_pag-, accessed 10.12.2020.

2. J. Reyna, J. Hanham, P. Meier, E-Learning and Digital Media, 15(1), 36 (2018)

3. A.G. Asmolov, Personality as the subject of psychological research (MSU, Moscow, 2006)

4. N.A. Alexeyev, Personality-oriented school (Phoenix, Rostov n/D, 2006)

5. N. Beetle, Headmaster, 2, 53 (2006)

6. M.I. Lukyanova, Head, 2, 5 (2006)

7. V.P. Bespalko, Accompanying Teaching Technology (Educator, Moscow, 1999)

8. A.K. Kolechenko, Encyclopedia of Educational Technologies: Teacher's Manual (CARO, St. Petersburg, 2002) 
9. C. N. Poulos, Qualitative Inquiry, 8 (3), 288 (2002)

10. G.K., Selevko, Traditional pedagogical technology and its humanistic modernization (School Technology Research Institute, Moscow, 2005)

11. E. Tikhomirova, Live learning: What is e-learning and how to make it work (Alpina Publisher, Moscow, 2016)

12. D. Tosh, B. Werdmuller, Creation of a learning landscape: weblogging and social networking in the context of e-portfolios 2018, https://docplayer.net/7520363Creation-of-a-learning-landscape-weblogging-and-social-networking-in-the-contextof-e-portfolios.html

13. Y. Huang, G. Huang, J. Materials Sci. and Engineering, 750(1), 609 (2020)

14. Z. Wang, J. Advances in Intelligent Systems and Computing, https://www.researchgate.net/publication/334819720

15. I.I. Burlakova, D. Dze, Scientific and practical J, 4 (275), 113(2019)

16. I.I. Burlakova, Int. Sci. Gazette, 3, 17(2015)

17. N.A. Razina, Head, 3, 125(2002) 